\title{
On Constructing a Knowledge Management Pyramid Model
}

\author{
Ying-Hsun Hung ${ }^{1,2}$; Seng-Cho T. Chou ${ }^{2}$ \\ Department of Information Management, National Taiwan University ${ }^{2}$ \\ Department of Management Information System, Hwa-Hsia Institute of Technology ${ }^{l}$ \\ d90003@im.ntu.edu.tw' ; chou@ntu.edu.tw ${ }^{2}$
}

\begin{abstract}
In this knowledge-based economy, knowledge has become an important asset to an organization and, consequently, knowledge management has emerged as an issue managers have to deal with. Peter F. Drucker (1993) said that knowledge will be the only competitive resource for companies in the future. This is an era in which knowledge plays a dominant role in our daily business lives. Intellectual capital has gradually taken the place of traditional tangible capital in many business organizations. However, practitioners are often puzzled about where they stand, how well they are doing, and what they should do next. This paper aims to construct a knowledge management maturity model as a means to help answer these and related questions.
\end{abstract}

There are three components in the proposed model: maturity levels, knowledge management processes, and knowledge management capabilities or enabling infrastructures. The maturity levels are based on the capability maturity model (CMM) of SEI. This model divides the knowledge management process into four main sub-processes: knowledge creation, knowledge storage, knowledge sharing, and knowledge application, emphasizing the need for continuous process improvement. Furthermore, knowledge management enablers are integrated into KMMM to describe how it supports the practices at each maturity level. The applicability of this model is evaluated through case studies, which also serve to illustrate how knowledge management practices among organizations are compared, and what maturity paths organizations can follow. Three Banks were taken for cases study through in depth interview with their senior managements. By analyzing data gathered through the process described above, the conclusion of this study is induced.

Keywords: knowledge management, knowledge management maturity model, knowledge management process, maturity model

\section{Introduction}

Peter F. Drucker (1993) said that knowledge will be the only competitive resource for companies in the future. This is an era in which knowledge plays a dominant role in our daily business lives. Intellectual capital has gradually taken the place of traditional tangible capital in many business organizations.

A recent KPMG survey (KPMG 2003) showed that $78 \%$ of respondents believe they are currently missing out on business opportunities by failing to successfully exploit available knowledge. Knowledge management $(\mathrm{KM})$ is being applied in all business and functional areas, with a focus on service delivery (53\%), marketing and sales $(53 \%)$, operations $(51 \%)$, human resources $(43 \%)$, R\&D (43\%), strategy (36\%), distribution channels (32\%), and procurement $(26 \%)$. Internal communities of practice (45\%), competence centres $(41 \%)$, information centres $(41 \%)$, and document databases $(41 \%)$ have been started in the last two years. The focus will shift from internal to external knowledge sharing and customer and supplier communities in the coming years.

In this so-called knowledge-based economy, knowledge has become an important asset to an organization and, consequently, knowledge management has emerged as an issue managers have to deal with. However, practitioners are often puzzled about where they stand on the roadmap of the KM journey, how well they are doing, and what they should do next. To help answer these and other related questions, we believe a maturity model would be an asset.

Maturity models describe the development of entities over time. Each entity develops through the levels over time until it reaches the highest, optimized, level. Knowledge management maturity (KMM) has been a major topic of research in recent years (Ehms and Langen 2002; Klimko 2001; Kochikar 2000; KPMG 2003). In practice, a few KMM models (KPMG 2003) have been proposed by consulting firms as well. However, a common KMM model that both academics and practitioners agree on has yet to materialize, while details are often missing from models in practice. Most KMM models copy the spirit of the Capability Maturity Model 
(CMM) (CMMI Product Team 2002) of SEI with its five levels of maturity -- initial, repeated, defined, managed, and optimizing. Capability, another important attribute of $\mathrm{CMM}$, can be translated into the enabling factors or infrastructure of KM. While most KMM models treat KM as a holistic activity, we view it as a process and expand it into four main $\mathrm{KM}$ sub-processes, namely knowledge creation, knowledge storage, knowledge sharing, and knowledge application. The added dimension allows us to gain better insight into how KM practices are supported at each maturity level and reflects our emphasis on the need for continuous process improvement.

The KMM model proposed in this study helps to answer the questions raised above. It assesses what KM capabilities an organization possesses, which maturity level the organization is at with respect to each of the KM capabilities, and what improvements the organization should be considering. In addition, it is the aim of this study to use this model to assess the differences of KM practices among organizations and serve as the basis for sector analysis and comparison.

The applicability of the proposed model is evaluated through a case study of $\mathrm{KM}$ practices in the banking industry in Taiwan. Three large local banks were selected, and in-depth interviews with their senior management were conducted. The details and interesting findings of this case study are presented in a subsequent section.

\section{Five Maturity Levels of Knowledge Management}

Most KMM models follow the five maturity levels defined in CMM. The definition of Ehms et al.(2002) is a good reference:

\section{Maturity Level 1 "initial"}

Processes are not consciously controlled; "successful" knowledge related activities are seen as a strike of luck and not as the result of goal-setting and planning.

\section{Maturity Level 2 "repeatable"}

Organizations have recognized the importance of knowledge management activities for their business. Organizational processes are partly described as knowledge management tasks and, by virtue of ideas from individual "KM pioneers"; pilot projects of KM typically exist.

\section{Maturity Level 3 "defined"}

Stable and practiced activities which effectively support the KM of individual parts of the organization. These activities are integrated in the day-to-day work processes and the corresponding technical systems are maintained.

\section{Maturity Level 4 "managed"}

Indicators relating to the efficiency of these robust KM activities are regularly measured. The activities are secured in the long term by organization-wide roles and compatible socio-technical KM systems.

\section{Maturity Level 5 "optimizing”}

The measuring instruments combine with other instruments for strategic control. There are no challenges left that cannot be solved with the established knowledge management tools.

\section{Knowledge Management Capabilities}

Gold et al. (2001) examined the issue of effective knowledge management from the perspective of organizational capabilities. It is suggested, as shown in Fig. 1, that a knowledge infrastructure consisting of technology, structure, and culture along with a knowledge process architecture of acquisition, conversion, application, and protection are essential organizational capabilities for effective knowledge management.

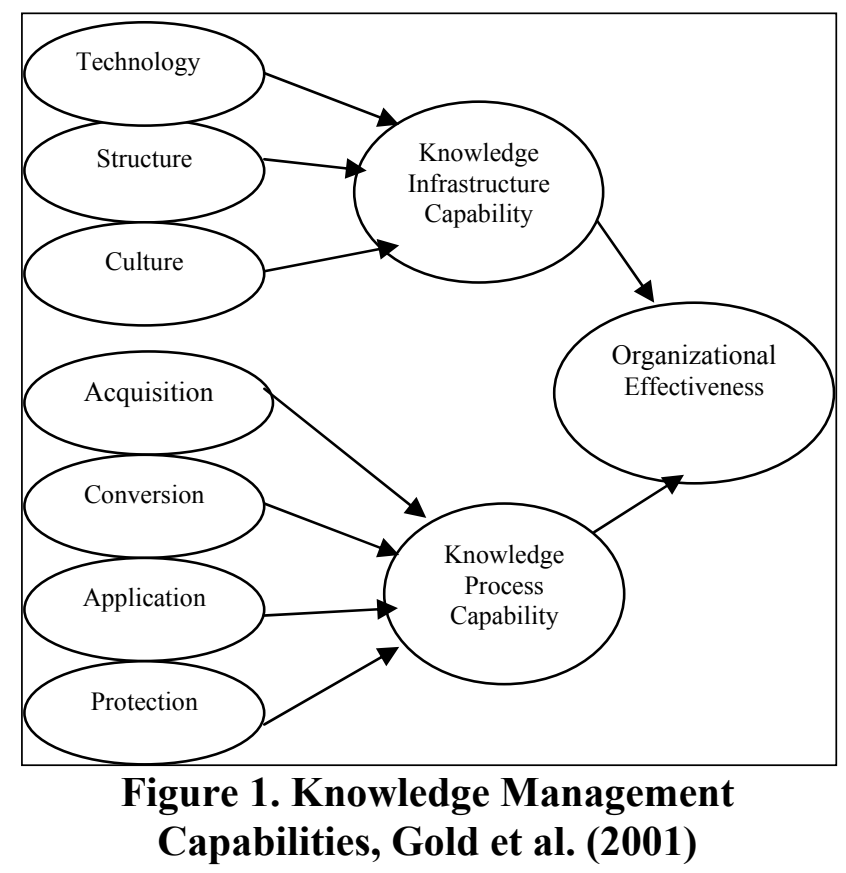

\section{Knowledge Management Processes}

Alavi et al. (2001) developed a systematic framework that is used to further analyze and discuss the potential role of information technologies in organizational 
knowledge management. This framework is grounded in the sociology of knowledge and is based on the view of organizations as social collectives and "knowledge systems." According to this framework, organizations as knowledge systems consist of four sets of socially enacted "knowledge processes": (1) creation, (2) storage/retrieval, (3) transfer, and (4) application. This view of organizations as knowledge systems represents both the cognitive and social nature of organizational knowledge and its embodiment in the individual's cognition and practices, as well as the organizational practices and culture.

\section{KMM from The Perspectives of Maturity, Capability, and The KM Process}

There are three components in our proposed KMM model, namely, maturity levels, knowledge management processes, and knowledge management capabilities or enabling infrastructures, representing a three dimensional model. The maturity levels are based on the capability maturity model of SEI. Specifically, we follow Ehms's (2002) maturity definitions with five levels, i.e., initial, repeated, defined, managed, and optimizing. We further look into generic and specific needs at each level.

From the capability perspective, we focus on three key enabling infrastructures, i.e., technical, structural, and cultural, after the study by Gold et al. (2001). The structural infrastructure makes reference to the presence of norms and trust mechanisms. The cultural dimension is built upon a sharing context. The technological dimension addresses the technology-enabled infrastructures that exist within the firm. These three knowledge management enablers play a critical role in supporting knowledge management activities at each maturity level.

$\mathrm{KM}$ activities and practices are assessed from a process perspective, giving an important third dimension to our model. Among the many proposed multi-stage KM process models, we adopted that of Alavi et al.(2001) with four key sub-processes, namely, knowledge creation, knowledge storage, knowledge sharing, and knowledge application. These four sub-processes are common to most $\mathrm{KM}$ process models in the literature and comprehensively cover the daily $\mathrm{KM}$ activities in a business setting.

This three-dimension KMM model can be unfolded and re-oriented into a KMM modeling template. This template is meant to be a survey vehicle for assessing the KM maturity of an organization. In this study, we focus on an organization's KM capabilities as revealed by its $\mathrm{KM}$ activities done against the objectives set at each maturity level. An organization is determined to reach a certain maturity level when its KM practices meet both the generic and specific objectives set at that level.

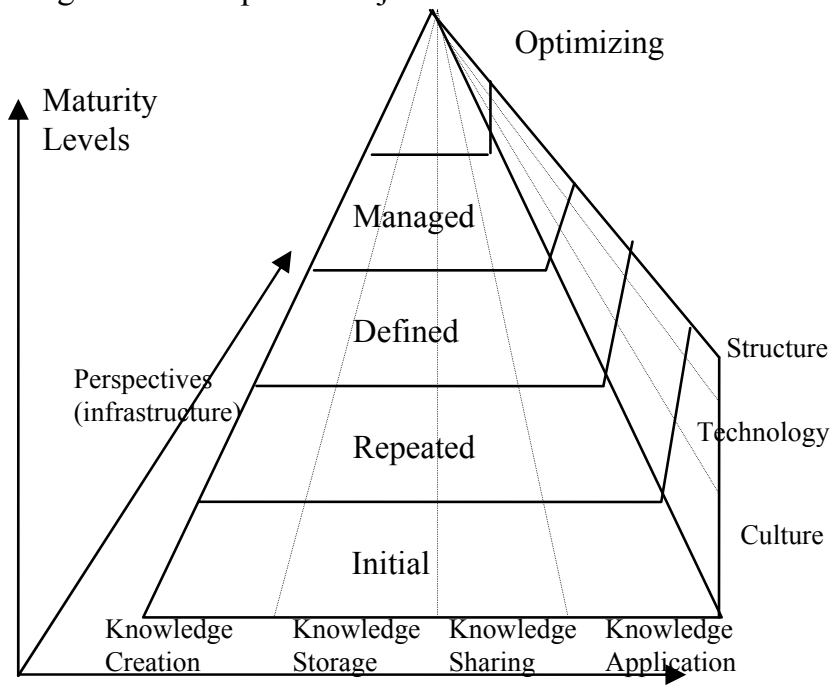

Figure 2 . The KMMM Pyramid Model

\section{Holistic Measurement Framework of KMMM and Surveying Table}

The holistic measurement framework of KMMM comprises knowledge management process and knowledge management enablers, and knowledge management maturity model. In the element-relationship diagram of KMMM, we can measure the maturity level of knowledge management practices in relation to organizations.

Therefore, Organizations can survey the fulfillment of knowledge management sub-processes in the specific business practices to discriminate and assess the maturity level of knowledge management sub-processes, so as to get a clear understanding of weaker key areas within knowledge management process and assist to rearrange the priorities of KM investments.

According to holistic measurement framework of KMMM ,we develop a surveying table to take down the actual state of practiced activities of knowledge management .This surveying table is drawn from three dimension: knowledge management process and knowledge management enablers, and knowledge management maturity model and represent the current state of specific practices and activities, generic practices and activities. By mapping generic objectives and specific objectives of each maturity level with the current state of specific practices and activities, generic practices and activities, we determine and assess the level of KMMM 
of organization by surveying the fulfillment degree of specific and generic practiced activities.

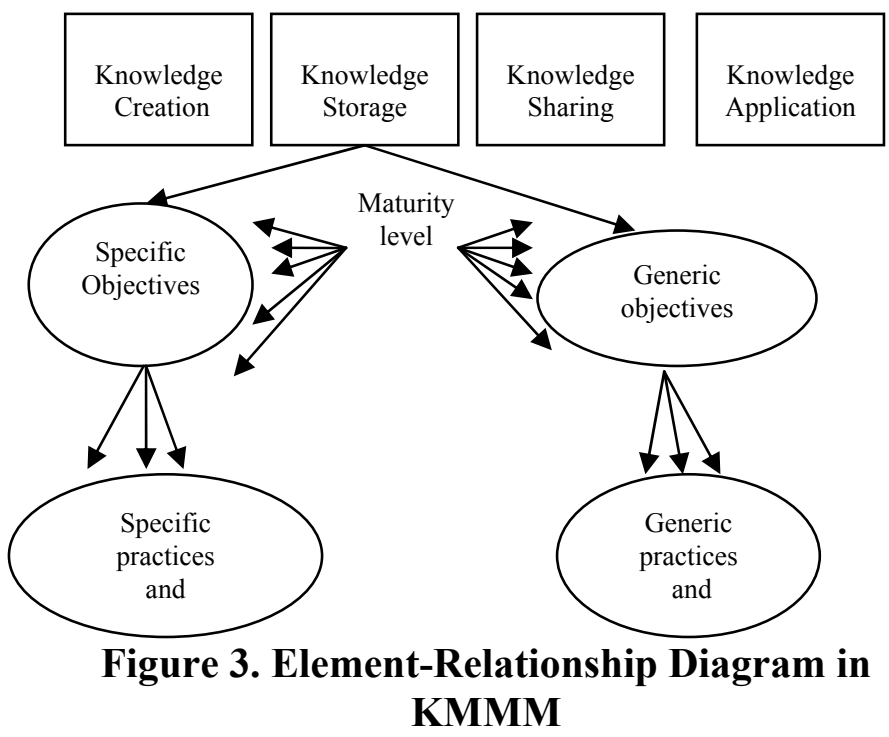

\section{Research Method}

A research method is a strategy of inquiry which moves from the underlying philosophical assumptions to research design and data collection. The choice of research method influences the way in which the researcher collects data. Specific research methods also imply different skills, assumptions and research practices (Myers 1997).

Case study research is the most common qualitative method used in information systems (Orlikowski and Baroudi, 1991). Although there are numerous definitions, Yin (2002) defines the scope of a case study as follows: A case study is an empirical inquiry that: investigates a contemporary phenomenon within its real-life context, especially when the boundaries between phenomenon and context are not clearly evident (Yin 2002).

Clearly, the case study research method is particularly well-suited to IS research, since the object of our discipline is the study of information systems in organizations, and "interest has shifted to organizational rather than technical issues" (Benbasat et al. 1987).

In order to establish foundation of this research, we searched literature review from the knowledge management maturity model and knowledge management process . The analysis is divided into three parts: maturity levels, knowledge management process, and knowledge management enablers. Research method mainly utilizes literature review and case studies. Selected case study companies (Bank A,B,C) were chosen for their practice characteristics and objectiveness of information. Study tool mainly uses extensive interview and data analysis as the main focus.

\section{Procedures of KMMM Assessment}

Ehms and Langen (2002) developed a KMMM Assessment Procedure that is used to further analyze and discuss how far they have been met for each of these topics special requirements have been formulated

The whole procedure is divided into six phases, as shown in Fig. 4. We adopted this version of KMMM Assessment Procedures .

\section{Phase 1 "Orientation \& Planning"}

The expectations of the organization or organizational unit with regard to the KMMM are clarified. The procedure is "defined" and planned exactly for each individual case.

\section{Phase 2 "Motivation \& Data Collection"}

The information is essentially acquired through workshops and interviews based on the structure of the KMMM.

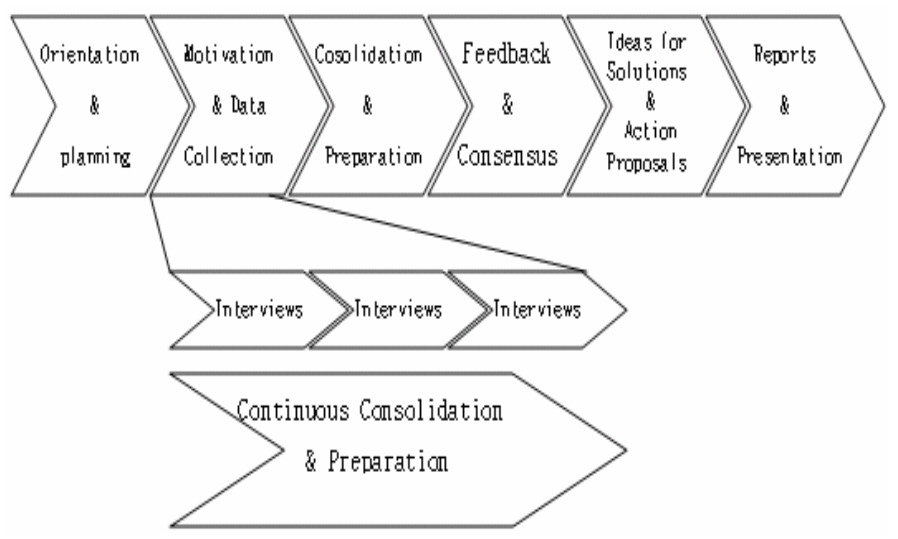

Figure 4. Procedures of KMMM Assessment

\section{Phase 3 "Consolidation \& Preparation"}

Several comprehensive knowledge-management expertise use their experience and intuition to ascertain which topics need more focus and how to do this. Comments are written on the assessments.

\section{Phase4 "Feedback \& Consensus"}

Results are discussed and consensus is reached between the interpretations made by the consultants and the organization members.

Phase5 "Ideas for Solutions \& Action Proposals " Detailed identification of the causes and further project planning is investigated. 
Phase6 "Report \& Presentation "

After the discussion of the results, the final report is drawn up.

\section{Case Studies}

To evaluate the applicability of the proposed KMM model, we study the local banking industry. Although IC design, software development, and banking are major knowledge intensive industries in Taiwan, banking industry is particularly interesting because of its size and competition, the intensity of professional knowledge involved and the application of information and $\mathrm{KM}$ technologies.

Three major local banks were chosen and in-depth interviews with their senior management were conducted for evaluation purposes. Each interview session was audio taped for subsequent analysis. A summary of the participants from the three banks and the survey results are shown in Table 1 below. The scores reflect the coverage of organizations' $\mathrm{KM}$ activities in particular business contexts.

Table 1. A summary of the interview

\begin{tabular}{|c|c|c|c|c|c|}
\hline \multirow{4}{*}{$\begin{array}{l}\text { Bank } \\
\text { A }\end{array}$} & Abbreviation & Department & Position & $\begin{array}{l}\text { Work } \\
\text { Experience }\end{array}$ & $\begin{array}{l}\text { Industry } \\
\text { Experience }\end{array}$ \\
\hline & MR. AA & Trust department & Manager & NA & NA \\
\hline & MR. AB & IT department & $\begin{array}{l}\text { IT } \\
\text { specialist }\end{array}$ & 9 years & 9 years \\
\hline & Ms. AC & $\begin{array}{l}\text { Corporate } \\
\text { Banking } \\
\end{array}$ & $\begin{array}{l}\text { Financing } \\
\text { Specialist }\end{array}$ & 6 years & 9 years \\
\hline \multirow{3}{*}{$\begin{array}{l}\text { Bank } \\
\text { B }\end{array}$} & MR. BA & Retail Banking & $\begin{array}{l}\text { Assistant } \\
\text { Manager }\end{array}$ & NA & NA \\
\hline & Ms. BB & Retail Banking & $\begin{array}{l}\text { Trust } \\
\text { Specialist }\end{array}$ & NA & NA \\
\hline & Ms. BC & MIS & $\begin{array}{l}\text { IT } \\
\text { Specialist }\end{array}$ & 10 years & 10 years \\
\hline \multirow{3}{*}{$\begin{array}{l}\text { Bank } \\
\text { C }\end{array}$} & MR. CA & Retail Banking & $\begin{array}{l}\text { Senior } \\
\text { Assistant } \\
\text { Manager }\end{array}$ & 7 years & 14 years \\
\hline & Ms. CB & \begin{tabular}{|l|} 
Corporate \\
Banking \\
\end{tabular} & Director & 6 years & 15 years \\
\hline & Ms. CC & Retail Banking & $\begin{array}{l}\text { Trust } \\
\text { Specialist }\end{array}$ & 8 years & 10 years \\
\hline
\end{tabular}

The survey results show that our KMM model is an effective vehicle to describe the current state of knowledge management activities practiced by the targeted banks. The results also suggest that Bank B is at maturity level 3 and Bank A and C at level 2 (weakness in generic activities at level 3 ) and 1 (weakness in generic activities at both levels $2 \& 3$ ) respectively. Bank B is the most aggressive bank among the three surveyed with respect to knowledge management practices with formalized mechanisms for knowledge creation and formalized channels for knowledge sharing with special attention paid to security issues. It encourages spontaneous knowledge sharing among employees and puts emphasis on knowledge documentization. The executive officers of Bank B also highly advocates knowledge management by encouraging the participation of subordinates and participate in the knowledge management practices themselves. We can easily point out the differences in invested efforts among the banks selected.

\section{Conclusion and Future Work}

We have constructed a knowledge management maturity model from the perspective of knowledge management process, and integrated knowledge management enablers into the model. The model can be used to evaluate how well organizations do in knowledge management, and to provide maturity paths that organizations can follow. The applicability of this model is evaluated through case studies, which also illustrate how knowledge management practices among organizations are compared.

\section{References}

[1] Alavi, M ., and Leidner, D.E. "Review: Knowledge Management and Knowledge Management Systems: Conceptual Foundations and Research Issues," MIS Quarterly (25:1), 2001,pp. 107-136.

[2] APQC. "APQC's Road Map to Knowledge Management Results: Stages of Implementation".

[3] Arthur Andersen , and APQC. "The Knowledge Management Assessment Tool, " Prototype Version, Released at the Knowledge Imperative Symposium, Houston, Texas, September ,1995.

[4] Beckman ,T. “A Methodology for Knowledge Management," Proceeding of the IASTED International Conference on AI and Soft Computing ,1997.

[5] Benbasat, I.,and Goldstein, D.K. and Mead, M. "The Case Research Strategy in Studies of Information Systems," MIS Quarterly (11: 3), 1987, pp. 369-386.

[6] CMMI Product Team. "Capability Maturity Model Integration (CMMISM), Version 1.1,” 2002.

[7] Drucker, P.F. Post Capitalist Society , New York, HarperBusiness, 1993. 
[8] Ehms, K ., and Langen, M. "Holistic Development of KM with KMMM," Siemens AG / Corporate Technology Knowledge Management, and Business Transformation , 2002.

[9] Gold, A. H., Malhotra, A., and Segars, A. H. "Knowledge Management: An Organizational Capabilities Perspective," Journal of Management Information Systems (18: 1), 2001, pp. 185-214.

[10] Klimko, G. "Knowledge Management and Maturity Models: Building Common Understanding," ECKM, 2001, pp. 269-278.

[11] Kochikar. "The Knowledge Management Maturity Model - A Staged Framework for Leveraging Knowledge," The KM World 2000 conference , Infosys, September 2000.

[12] KPMG. "The Knowledge Journey: A Business Guide to Knowledge Systems,"1999.

[13] KPMG. "KM research report ," 2000.

[14] KPMG. "KPMG's Knowledge Management Survey 2002/2003," 2003

[15] LAW, Y. F., and LEE, J. E. "Exploring Knowledge Management Perceptions among Information Systems Managers-Empirical Sense-Making Through Focus Group Research," Australian Journal of Information Systems, Dec., 2001, pp. 42-55.

[16] Myers, M. D. "Qualitative Research in Information Systems,” MIS Quarterly (21:2) ,1997, pp. 241-242.

[17] Nissen, M. E., Kamel, M. N., and Sengupta, K. C. "Toward Integrating Knowledge management, Processes and Systems: A Position Paper," Naval Postgraduate School, USA ,1999.

[18] O'Dell, C. "A Current Review of Knowledge Management Best Practices," Business Intelligence, London ,1996.
[19] Orlikowski, W.J., and Baroudi, J.J. "Studying Information Technology in Organizations: Research Approaches and Assumptions," Information Systems Research (2) ,1991, pp. 1-28.

[20] Skyrme, D. J. "Knowledge Management SolutionsThe IT Contribution," SIGGROUP Bulletin, April, (19:1),1998.

[21] Wiig ,K. "Knowledge Management Foundations," Arlington: Schema Press, 1993.

[22] Yin, R. K. Case Study Research, Design and Methods, 3rd ed. Newbury Park, Sage Publications, 2002.

[23] http://www.sei.cmu.edu/cmmi/

[24] http://www.kmmm.org 